\title{
A Re-examination of Precipitation Activity in the Subtropics and the Mid-latitudes Based on Satellite-derived Data
}

\author{
Yasu-Masa KODAMA \\ Department of Earth and Environmental Sciences, Hirosaki University, Hirosaki, Japan \\ and \\ Atsushi TAMAOKI ${ }^{1}$ \\ Department of Earth Sciences, Graduate School of Hirosaki University, Hirosaki, Japan
}

(Manuscript received 7 December 2001, in revised form 12 July 2002)

\begin{abstract}
Large-scale precipitation activity in the subtropics and the mid-latitudes, in addition to seasonal variation, were studied using new climatological precipitation datasets: GPCP rain gauge-satellite combined data, and TRMM level-3 data derived from TRMM-PR observations.

We found significant large-scale precipitation zones extending between the subtropics and the midlatitudes, referred to as SMPZs (Subtropical Mid-latitude Precipitation Zones) in this study. Most portions of the SMPZs existed over the oceans. Meridional variation of zonal averaged precipitation was quite different between land and the oceans. Mid-latitude peaks at $\sim 40^{\circ}$ in zonal averaged precipitation were observed only over the oceans, because the SMPZs over the ocean formed the $40^{\circ}$ peaks. The midlatitude peaks significantly intensified in the fall and winter when the SMPZs zonally extended in the mid-latitudes and kept precipitation as substantial as in summer. In summer, the SMPZs extended diagonally across the subtropics from the active tropical monsoon rainfall areas. Precipitation over the subtropical oceans thus increased in summer. Over land, mid-latitude peaks were not found. Precipitation intensified in summer, both in the subtropics and in the mid-latitudes.

The mid-latitude portions of the SMPZs extended near the storm tracks defined by high baroclinic wave activity. However, many portions of the SMPZs shifted to the lower latitudes from the storm tracks in fall and winter. In summer, baroclinic wave activity was weak for the subtropical portions of the SMPZs, which were characterized by convergence and frontal zones with weak baroclinicity. Vertical structure of precipitation observed by PR suggested that deep (shallow) stratiform and convective precipitation largely contributed to the active rainfall along the SMPZs in summer (fall and winter). A possible relationship between the shallow precipitation and the displacement of the SMPZs from the storm tracks in fall and winter was discussed.
\end{abstract}

\section{Introduction}

Global distribution of precipitation is the basic information to describe water circulation

Corresponding author: Yasu-Masa Kodama, Department of Earth and Environmental Sciences, Hirosaki University, 3 Bunkyo-cho, Hirosaki 0368561, Japan.

E-mail: kodama@cc.hirosaki-u.ac.jp

1 Present affiliation: Weather and Marine Division, Yoshida Sangyo Corporation.

(C) 2002, Meteorological Society of Japan on the Earth. Many efforts have been made to obtain reliable climatological data on precipitation. Such efforts are also necessary for examining the performance of general circulation models (GCMs) for climatic studies, because a large difference exists among the climate models for tropical and mid-latitude precipitation (Gates et al. 1999). Although several climatic studies on global precipitation were conducted using surface observations (Jaeger 1976, hereafter J76; Legates and Willmott 
1990, hereafter L\&W), questions of reliability remain for the maritime portions, because quantitative observation of precipitation by volunteer vessels is difficult due to technical reasons, as mentioned by Janowiak et al. (1995). Recently more than 20 years of satellite observations by passive IR and microwave sensors were examined and useful techniques to evaluate the precipitation from these data were developed. Several global climatic datasets for precipitation derived from these satellite observations were released, such as the Global Precipitation Climatological Project (GPCP) by Huffman et al. (1997) and the National Oceanic and Atmospheric Administration (NOAA) Climate Prediction Center Merged Analysis of Precipitation (CMAP) by Xie and Arkin (1997). In late 1997, the Tropical Rainfall Measuring Mission (TRMM) was launched and epochmaking observations by space-born Precipitation Radar (PR) started. Since PR is an active sensor, which observes precipitation particles directly, it can improve the reliability of precipitation estimates over both land and ocean. Moreover, intercomparisons among the observations by $P R$, and by other passive IR and microwave sensors on board the TRMM, are useful for determining the reliability of previous methods for precipitation estimation by passive satellite observations.

Recent progress makes it possible to discuss large-scale precipitation activity quantitatively over both land and ocean. Several studies on global precipitation were made using the satellite-derived datasets. Xie and Arkin (1997) analyzed the CMAP data, compared to the climatologies derived from surface observations (J76 and L\&W), and pointed out the existence of significant precipitation zones over oceans developed around the storm tracks in every data, although precipitation intensity along the zones was largely different. These precipitation zones have been referred to as storm tracks by Xie and Arkin (1997), Janowiak et al. (1998), and Nakamura et al. (2001), although we will show that many portions of these zones are displaced from the storm tracks. We refer to these zones as Subtropical Mid-latitude Precipitation Zones (SMPZ), because they extend between the subtropics and the mid-latitude in summer, as will be shown later. Janowiak et al. (1998) compared the precipitation fields be- tween the GPCP and the NCEP-NCAR (National Centers for Environmental PredictionNational Center for Atmospheric Research) reanalysis. They found that the precipitation of the SMPZs was estimated weaker in the NCEP-NCAR reanalysis than in the GPCP. These climatic studies using satellite-derived data, however, have just started and their main target has been confined to the tropics. Quantitative research for large-scale precipitation activity in the subtropics and the mid-latitudes are expected.

In this study, we quantitatively examine the precipitation activity between $20^{\circ} \sim 60^{\circ}$ latitude and the seasonal variation using new climatological data for precipitation provided by the GPCP and the TRMM project. The study area includes the second strongest precipitation peaks in the mid-latitudes around baroclinic zones, although only the equatoward side of these peaks can be observed by TRMM. In particular, we examine the behavior and vertical structure of precipitation in the SMPZs. The relationship between the SMPZs and baroclinic activity is also studied.

In Section 2, the datasets utilized in this study are described. Large-scale distribution of annual mean precipitation and seasonal variation are examined in Sections 3 and 4, respectively. In Section 5, the relationship between the SMPZs and activity of baroclinic waves is studied. In Section 6, the vertical structure of precipitation in the SMPZs is studied, using PR observations. Section 7 presents the summary.

\section{Data}

We utilize the GPCP satellite-gauge combined monthly $2.5^{\circ} \times 2.5^{\circ}$ (latitude $\times$ longitude) grid precipitation data (Huffman et al. 1997; Huffman and Bolvin 2001) obtained from the National Climatic Data Center (NCDC)/NOAA via Internet access. This data is version 2 , and derived from global rain gauge data collected by Global Precipitation Climatology Center (GPCC) (Rudolf 1993), along with many kinds of precipitation indices derived from satellite observations, i.e., GPI (GOES Precipitation Index) based on IR atmospheric window observations by geostationary and polar-orbital satellites (Arkin and Meisner 1987), OPI (Outgoing longwave radiation based Precipitation Index) derived from polar-orbital satellite IR observa- 
tions (Xie and Arkin 1998), SSM/I (Special Sensor Microwave/Imager) scatter-based precipitation estimates based on $85 \mathrm{GHz}$ microwave observations (Ferraro 1997), SSM/I emission-based precipitation estimates using $19 \mathrm{GHz}$ and $23 \mathrm{GHz}$ observations (Wilheit et al. 1991), and a parameter based on TOVS (the Television Infrared Operational Satellite (TIROS) Operational Vertical Sounder) microwave observations (Susskind et al. 1997). Each data and index has advantages and defects. However, the GPCP satellite-gauge combined data is processed by well-organized algorisms, in which the defects of some data and/or indices are compensated by the merits of the other data and/or indices (Huffman et al. 1997). Model outputs are not included in the GPCP that are different from CMAP by Xie and Arkin (1997). Although the GPCP (version 2) provides global precipitation since 1979 , we exclude the period before 1987 for the analysis, because SSM/I observations have been adopted only for the period after July 1987.

We also analyze monthly $3 \mathrm{D}$ precipitation structures and monthly precipitation statistics using TRMM observations for the area between $37.5^{\circ} \mathrm{N}$ and $37.5^{\circ} \mathrm{S}$ with $5^{\circ} \times 5^{\circ}$ (latitude $\times$ longitude) grids. Version 5 of the following two products provided by the National Space Development Agency of Japan (NASDA), and the Goddard Space Flight Center (GSFC) of the National Astronautics and Space Administration (NASA) (NASA/GSFC, 2001) are utilized; one is the 3A25 product derived from PR observations, and the other is the $3 \mathrm{~A} 11$ product from TMI (TRMM Microwave Imager). Since the TRMM observations are confined to the zone of less than $\sim 36^{\circ}\left(\sim 37^{\circ}\right)$ in latitudes for PR (TMI), the grid-point values at $37.5^{\circ} \mathrm{N}$ and $37.5^{\circ} \mathrm{S}$ of these products are derived from the observations within $35^{\circ} \sim 36^{\circ}$ (3A25), and $35^{\circ} \sim 37^{\circ}$ (3A11) in latitude. The 3A25 product is derived from the $\mathrm{PR}$ observations, with a minimum detectable precipitation intensity of $\sim 0.5 \mathrm{~mm} / \mathrm{hr}$, and horizontal and vertical resolutions of $\sim 4 \mathrm{~km}$ and $250 \mathrm{~m}$, respectively. We utilize the following information in 3A25: rainfall classification categorized into convective and stratiform rain, echo-top height vertical histograms, and six-layered monthly precipitation intensities. Here, the echo-top height is defined as a maximum height, where precipita- tion is detectable in the three-consequent range bins of the PR observations. The rainfall classification is made by existence of bright bands, and the relationship between echo-top-height and freezing-level (NASA/GSFC 2001). Monthly precipitation intensity in the $3 \mathrm{~A} 11$ product is derived from nine-channel TMI observations by matching up to several atmospheric models.

Long-term averaged precipitation data for each month from J76 and L\&W are utilized as references for precipitation climatologies derived from surface observations. These are obtained from the data archive center of NCAR via Internet access. The major source for J76 was rain gauge observations over land and islands. Precipitation intensity over oceans was extrapolated from the observations for islands and coastal stations, and evaluated from precipitation frequency observed by vessels. L\&W combined the precipitation estimation by Dorman and Bourke $(1979,1981)$ over the Pacific and Atlantic Oceans, and those by J76 over the other oceans, and rain gauge observations over land. Here, Dorman and Bourke (1979, 1981) evaluated the precipitation using subjective observations of precipitation intensity and temperature reported by vessels. Time-periods for statistics are different among the datasets, i.e., 1931-1965 (J76), 1920-1980 (L\&W), 19882000 (GPCP), and 1998-2000 (TRMM). We also utilize climatic data of three-layered cloud amounts prepared by the International Cloud Climatology Project (ISCCP)-D2 data (Rossow and Schiffer 1999) to be compared to the precipitation fields. Monthly statistics from the NCEP-NCAR reanalysis data compiled by $\mathrm{Na}-$ kamura and Shinpo (personal communication), and of surface cyclones in the NH compiled by Serreze (1995), are utilized to examine baroclinic wave activities compared to the precipitation fields.

\section{Annual mean precipitation}

Figure 1 shows long-term averaged precipitation fields of the GPCP, J76 and L\&W. Hereafter, we confine our attention to the subtropics and the mid-latitudes between $20^{\circ}$ and $60^{\circ}$, although most figures in this paper include the tropics. In the GPCP, significant precipitation zones appear over oceans extending northeastward (southeastward) in the Northern (Southern) Hemisphere from the subtropics to the 

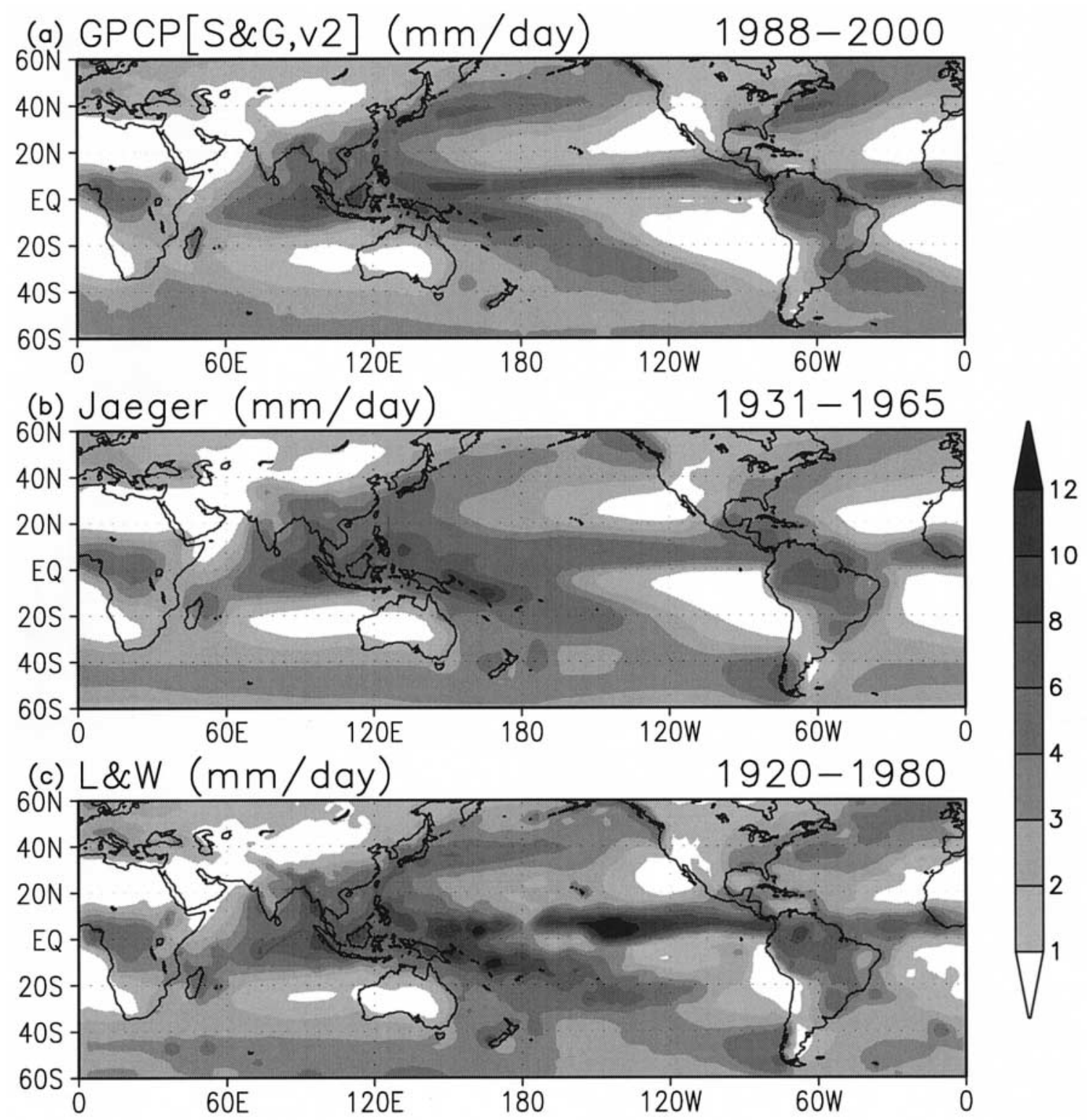

Fig. 1. Long-term averaged precipitation of the GPCP (satellite-gage combined, version 2) for 1988-2000 (a), Jaeger (1976) for 1931-2000 (b), and Legates and Willmott (1990) for 1920-1980 (c).

mid-latitudes over the North (South) Pacific and the North (South) Atlantic. These zones correspond to the SMPZs. The maximum precipitation intensity in these zones is $\sim 5 \mathrm{~mm} /$ day around $30^{\circ} \mathrm{S}$, and $\sim 7 \mathrm{~mm} /$ day around $40^{\circ} \mathrm{N}$. Although several SMPZs are also shown by $\mathrm{J} 76$ and $\mathrm{L} \& \mathrm{~W}$, precipitation intensity is represented weaker for the Southern Hemisphere (SH) in L\&W, especially over the South Atlantic, and for both hemispheres by $\mathrm{J} 76$.
Maritime precipitation represented by $\mathrm{J} 76$ and $\mathrm{L} \& \mathrm{~W}$, in which the precipitation of the SMPZs is weakly represented, seems to be questionable in several regions. For example, strong precipitation off the west coasts of Canada and Patagonia (the southern part of South America) shown in $\mathrm{J} 76$ and $\mathrm{L} \& \mathrm{~W}$ is not found in the GPCP, where strong precipitation is confined along the coast. Probably the precipitation is an artifact due to an inappropriate extrapolation 
Zonal Mean Precip.(mm/day) - GPCP $(1988-2000)$ (a) TOTAL
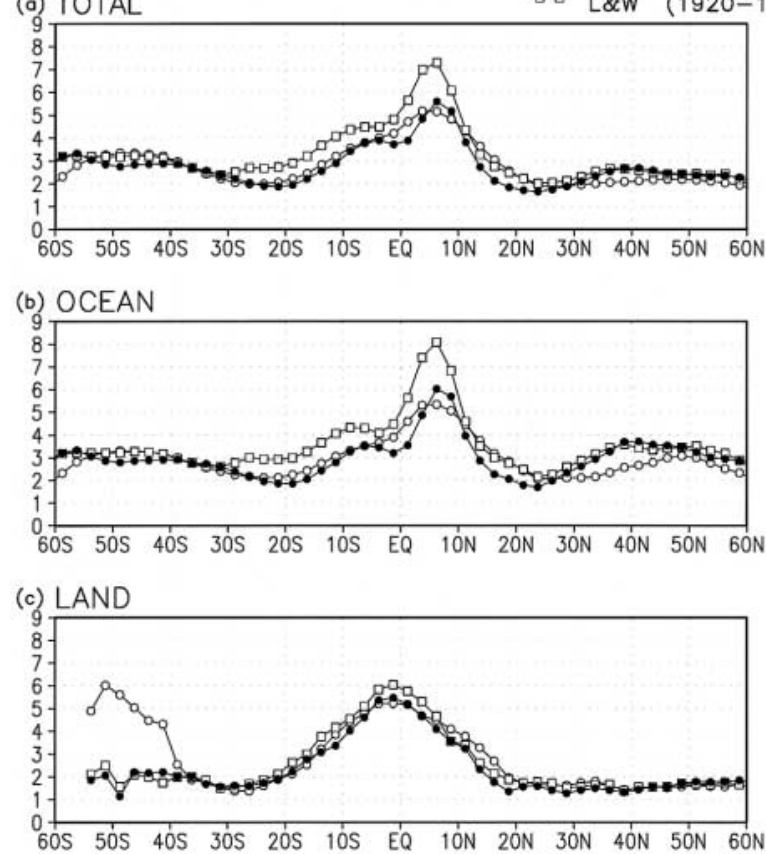

Fig. 2. Zonal mean precipitation for the GPCP (closed circles), Jaeger (open circles), and Legates and Willmott (open rectangles) (a). As in (a) except averaged over oceans including lakes (b) and over land (c). Statistical periods for each data are the same as in Fig. 1.

to the ocean of the strong coastal precipitation, because no island stations exist off these west coasts.

The difference in the represented SMPZs among the datasets produces variation in zonal averaged precipitation, shown in the top panel of Fig. 2. In the GPCP, mid-latitude peaks are found at $\sim 40^{\circ}$ latitude corresponding to the SMPZs over oceans. Although this peak in the $\mathrm{NH}$ is also represented in $\mathrm{L} \& \mathrm{~W}$ corresponding to the similar representation of the SMPZs in the $\mathrm{NH}$, the mid-latitudes peaks appear at $\sim 50^{\circ}$ in $\mathrm{L} \& \mathrm{~W}$ for the $\mathrm{SH}$, and in $\mathrm{J} 76$ for both hemispheres. Several previous articles (e.g., Trewartha and Horn 1980) remarked that the mid-latitude precipitation was larger in the $\mathrm{SH}$ than in the NH, as shown in J76 and L\&W. In the GPCP, however, mid-latitude precipitation is almost equal between the hemispheres, except for stronger precipitation around $60^{\circ} \mathrm{S}$.
Figure 2 also shows meridional variation in precipitation averaged over oceans (including lakes) and land for each dataset. It should be remarked that the mid-latitude peaks are found only over oceans; meridional distribution over land is almost flat except for a plausible peak around $50^{\circ} \mathrm{S}$ described in $\mathrm{J} 76$, probably due to insufficient observations over Patagonia, the sole landmass in this latitude (cf., Fig. 1-b). The meridional variation in the mid-latitudes, shown in the top panel, can be ascribed to the variation over oceans. This land-ocean difference in the meridional variation is due to the SMPZs extending almost exclusively over oceans. Besides Patagonia, meridional distribution over land almost agrees among the datasets, because rain gauge observations are utilized in all datasets over land, while satellite observations are largely reflected in the GPCP over oceans, where differences among the datasets is large, as similarly mentioned by Xie and Arkin (1997).

We also examine the SMPZs for longterm averaged precipitation from model outputs of the NCEP-NCAR and European Center for Medium Range Weather Forecasting (ECMWF) re-analysis systems. Although the SMPZs are detectable, their precipitation intensity is weakly represented especially in the NCEP-NCAR for the SH (not shown). Janowiak et al. (1998) already identified similar disagreement between the GPCP and the NCEP-NCAR.

Figure 3 shows three-year averaged precipitation fields derived from the PR and TMI observations compared to the result of the GPCP. Here the precipitation from TMI is obtained only over oceans, because the microwave emission method, unavailable over land, is utilized for the analysis, and PR and TMI can observe only the lower-latitude portions of the SMPZs. Except for several regional differences over the South Pacific, the precipitation distribution is similar among the three data. Figure 4 shows the meridional variations of zonal averaged precipitation. Meridional variations are well matched between the GPCP and PR over both land and oceans, especially over land. This agreement by independent satellites and variable sensors of TRMM reinforces the reliability of precipitation data provided by the GPCP.

In this section, we showed that the SMPZs were the most significant precipitation systems 


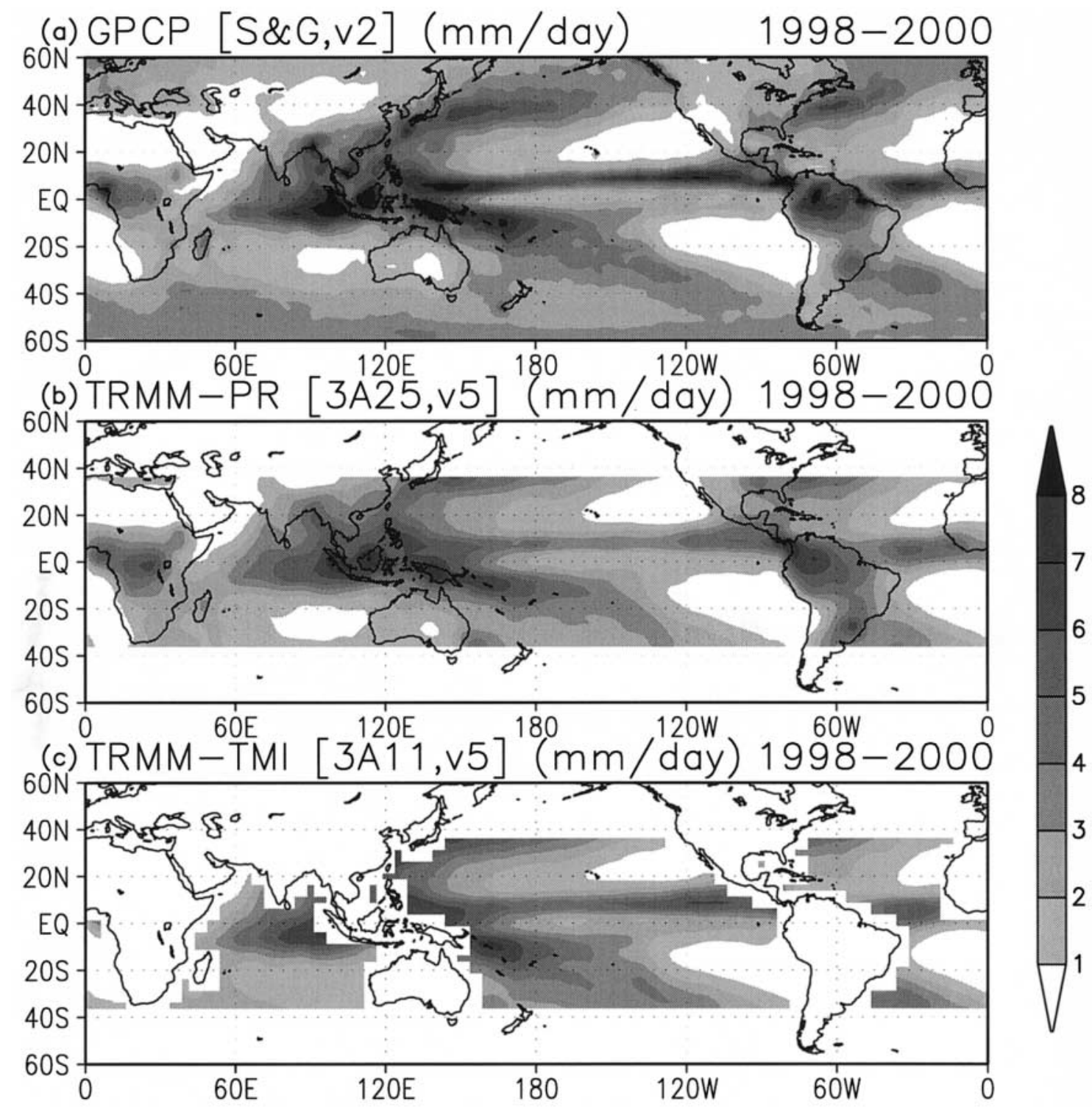

Fig. 3. As in Fig. 1 except for PR (b) and TMI (c). Statistical period is 1998-2000 for all data including the GPCP. Precipitation in the latitudes higher than $37.5^{\circ}$ is not shown for PR and TMI. Precipitation over land is not shown for TMI.

in the subtropics and the mid-latitudes based on satellite-derived data. The SMPZs form the mid-latitude peaks at $\sim 40^{\circ}$ latitude in zonal averaged precipitation differently from several previous climatological studies, which showed the peaks at $\sim 50^{\circ}$. Since most portions of the SMPZs existed over ocean, the mid-latitude peaks were observed only over ocean, and the meridional distribution over land was almost flat in the subtropics and the mid-latitudes.
The precipitation of the SMPZs was underestimated in the previous climatologies derived from surface observations, when we assumed high reliability of satellite-derived data. The agreement between the GPCP and TRMM data, derived from independent observations and methods, supported the reliability of these data over both land and oceans. Hereafter we will describe the precipitation activity of the SMPZs using the GPCP and TRMM data. 

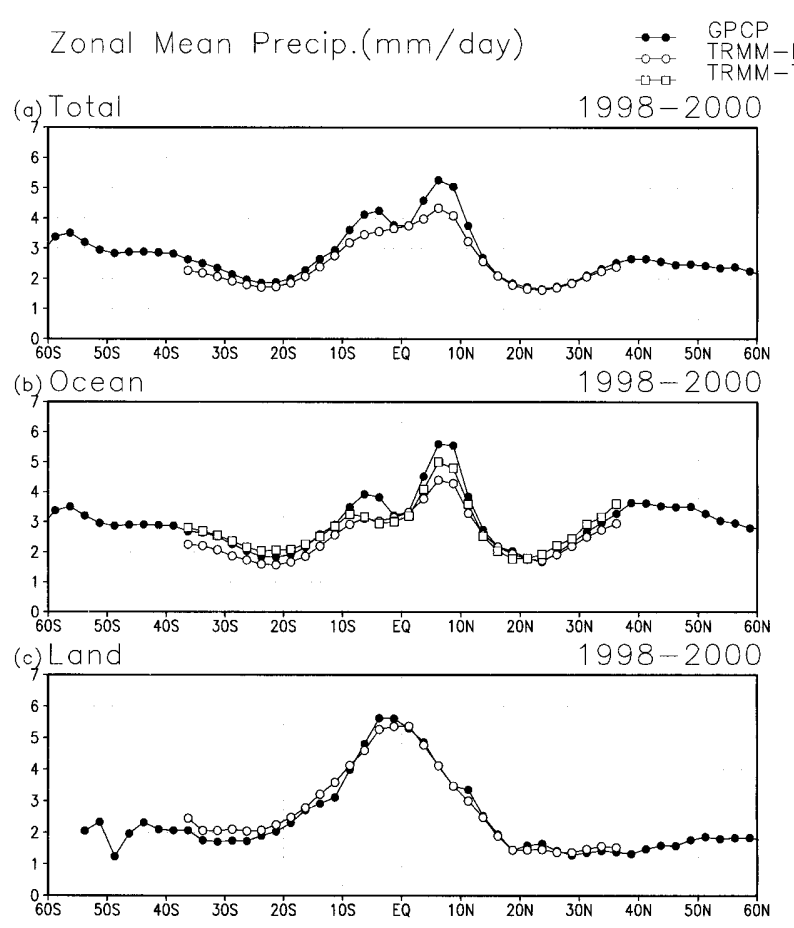

Fig. 4. As in Fig. 2 except for PR (open circles) and TMI (open rectangles; ocean only). Statistical period is 19982000 for all data.

\section{Seasonal variation}

Figure 5 shows seasonal variation of zonal averaged precipitation in the GPCP. Precipitation is stronger during the warm season in the subtropics at $20^{\circ} \sim 30^{\circ}$ latitude, and during fall and winter in the mid-latitudes at $\sim 40^{\circ}$. The summertime intensification in the subtropics is observed over both land and oceans, although the maximum appears $2 \sim 3$ months later over oceans than over land in the NH, i.e., in August to October over oceans, and in May to September over land. In the $\mathrm{SH}$, active precipitation starts around December over both land and oceans, and continues longer over ocean (until April) than over land (until March). The fallto-winter intensification of precipitation in the mid-latitudes is significant over oceans and obscure over land, especially in the NH. The fall to winter intensification is also found over land at $40^{\circ} \mathrm{S} \sim 50^{\circ} \mathrm{S}$, probably due to a local seasonal activation of precipitation over Patagonia. We confirm similar seasonal variations by independent observations of PR (Fig. 6) and TMI (not shown).

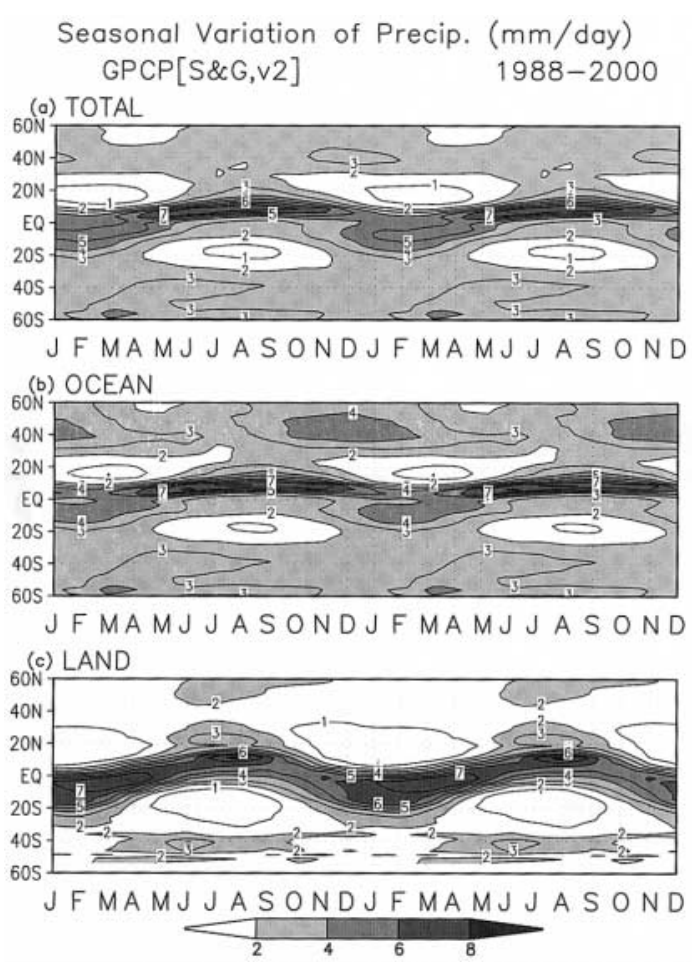

Fig. 5. Seasonal variation of zonal averaged precipitation over the whole earth (a), over oceans (b) and over land (c) derived from the GPCP data. Statistical period is 1988-2000. Two annual cycles are shown to observe the seasonal variation during the $\mathrm{NH}$ winter easily.

The fall-to-winter intensification of precipitation over mid-latitude oceans is related to the seasonal change in the SMPZs. Figure 7 shows long-term averaged fields of precipitation intensity in the GPCP for four months representing the seasons. The SMPZs are significant throughout the year. In summer, i.e., July in the $\mathrm{NH}$ and January in the SH, the SMPZs extend diagonally from active rainfall areas of tropical summer monsoons, although the SMPZ over the North Atlantic is somewhat weaker and disconnected to the tropical rainfall around Central America. These features are consistent with Kodama (1992, 1993), i.e., the subtropical portions of the SMPZs are significant quasistationary convergence zones in summer except for the SMPZ over the subtropical North Atlantic, which is also a convergence zone but appears only intermittently during summer. In fall and winter, October and January in the $\mathrm{NH}$ 


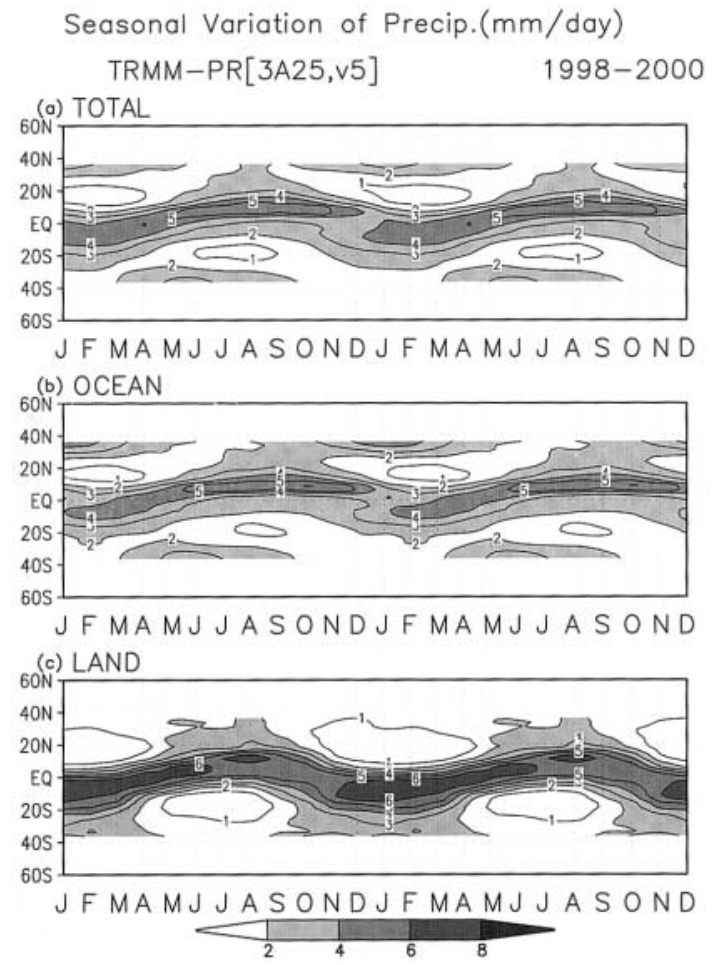

Fig. 6. As in Fig. 5 except for PR and statistical period is $1998-2000$. and April and July in the SH, the SMPZs are significant and zonally extend over the oceans around $40^{\circ}$ latitude in both hemispheres. The SMPZs are clearly separated from the tropical rainfall areas. Precipitation intensity exceeded $5 \mathrm{~mm} /$ day, and as strong as the SMPZs in summer. In spring, i.e., April (October) in the $\mathrm{NH}(\mathrm{SH})$, the horizontal extension of the SMPZs is similar to the summertime feature and precipitation is somewhat less intense than in summer.

Figure 8 is as in Fig. 7 except for the PR observations. We confirm similar seasonal variations in the GPCP, i.e., strong precipitation over ocean extends widely in the mid-latitudes at $\sim 35^{\circ}$ in fall and winter, and is confined to the western part of the oceans in summer. We also confirm similar results in the TMI observations (not shown). As shown in Figs. 6 and 7 , the zonal averaged maritime precipitation intensifies in the subtropics in summer, and in the mid-latitudes in fall and winter. This change can be ascribed to the seasonal variation of the SMPZs. The summertime intensification over subtropical ocean is ascribed to the connections between the SMPZs and the tropi-
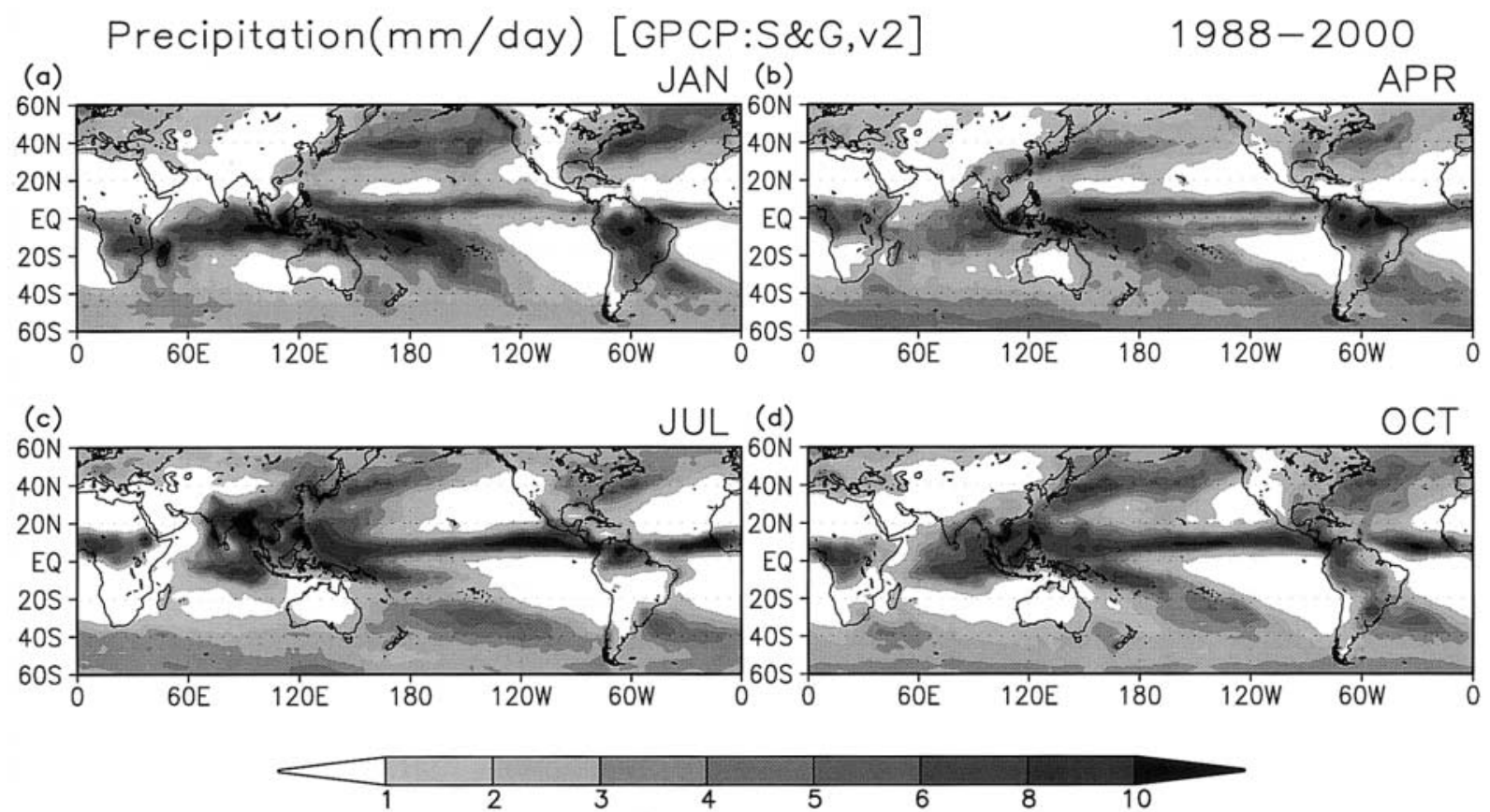

Fig. 7. Precipitation fields in January (a), April (b), July (c), and October (d) for the GPCP. Statistical period is $1988-2000$. 

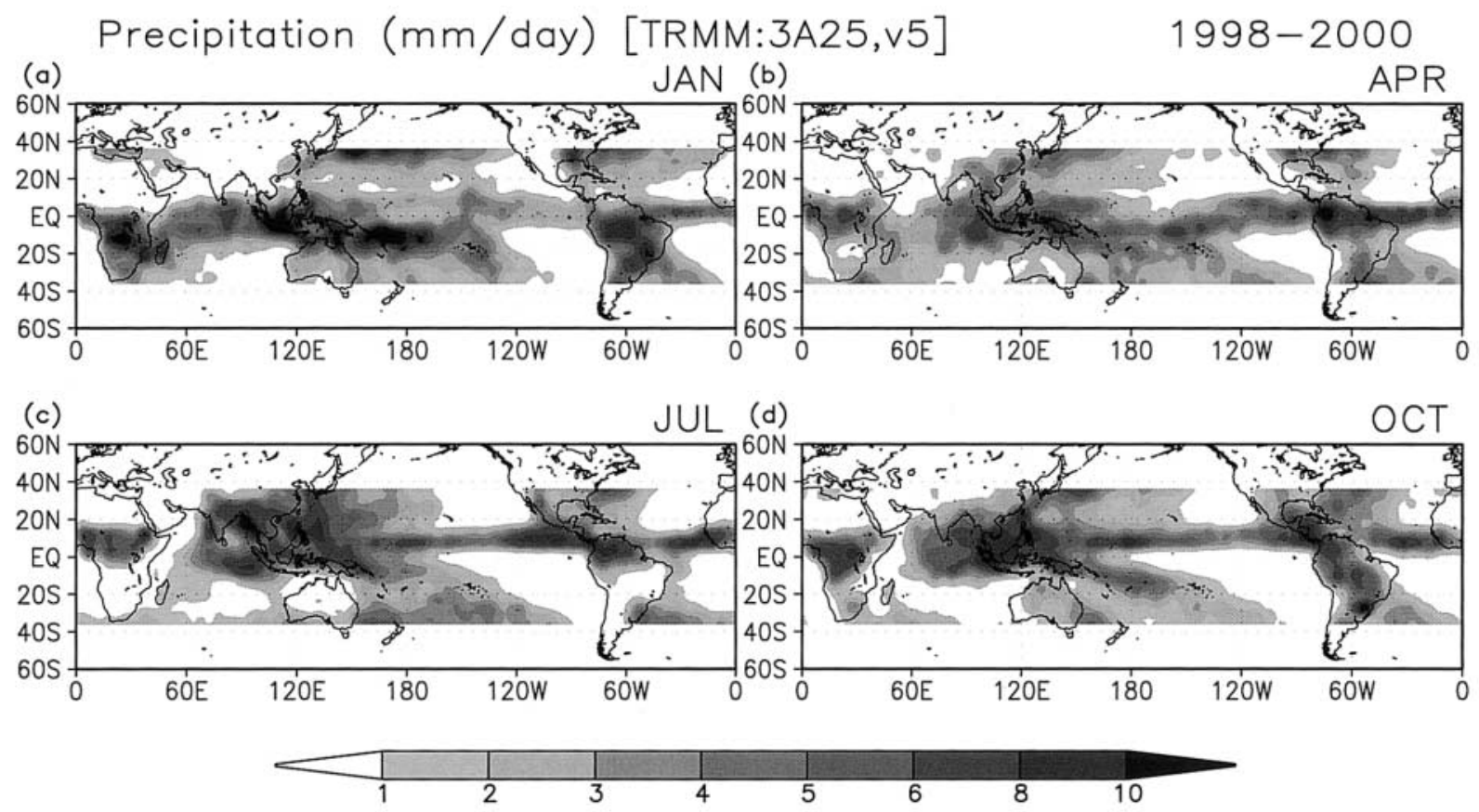

Fig. 8. As in Fig. 7 except for PR and statistical period is 1998-2000.

cal monsoon rainfall in summer, while the fall-to-winter intensification over mid-latitude ocean is ascribed to the directional change of the SMPZs to east-west in keeping with their strong precipitation as in summer.

The strong fall-to-winter precipitation of the SMPZs was partly represented in J76 and $\mathrm{L} \& \mathrm{~W}$ in the $\mathrm{NH}$, but not well in the $\mathrm{SH}$ especially over the South Atlantic (not shown). The strong precipitation is also found in the model outputs of ECMWF and NCEP-NCAR for both hemispheres (not shown). When we consider that ship observations are poorer in the $\mathrm{SH}$, results from $\mathrm{J} 76$ and $\mathrm{L} \& \mathrm{~W}$ for the $\mathrm{SH}$ oceans are plausible, and the strong fall-to-winter precipitation along the SMPZs is likely to exist.

Petty (1995) statistically analyzed longterm weather reports of volunteer vessels and showed that strong convection, or lightning reports, increased over the mid-latitude oceans in fall and winter. Recently, Kawasaki (personal communications) reported active lightning along the SMPZs in fall and winter from the lightning sensor observations of TRMM. These results suggest active convections around the SMPZs consistent with our findings on the strong precipitation along the SMPZs during these seasons.

\section{Relationship between the SMPZs and storm tracks}

Several previous studies identified the SMPZs as storm tracks (e.g., Xie and Arkin 1997; Janowiak et al. 1998, Nakamura et al. 2002), although the relationship between the SMPZs and storm tracks has not been clarified. Here, the SMPZs are compared to several indices representing the activity of baroclinic waves.

First, frequency of surface mobile cyclones in the NH is compared to the SMPZs using a dataset provided by Serreze (1995), averaged for 1979-1993 (left panels of Fig. 9), in summer and winter. In the Serreze dataset, a cyclone is detected as a grid point of minimum SLP, at least $2 \mathrm{hPa}$ lower than the surrounding points in NMC $47 \times 51$ Octagonal Grid. Since the size of the NMC grids range from $274 \mathrm{~km}$ at $20^{\circ} \mathrm{N}$ and $408 \mathrm{~km}$ at the North Pole, the minimum detection diameter of the closed SLP contour is $500 \sim 800 \mathrm{~km}$ and most meso-scale cyclones, e.g., polar lows, are out of the range for analysis. The maximum detection diameter is limited to $1600 \sim 2400 \mathrm{~km}$, and most planetaryscale cyclones are not the subjects. Therefore, synoptic-scale migratory cyclones are the major subjects of this dataset. 

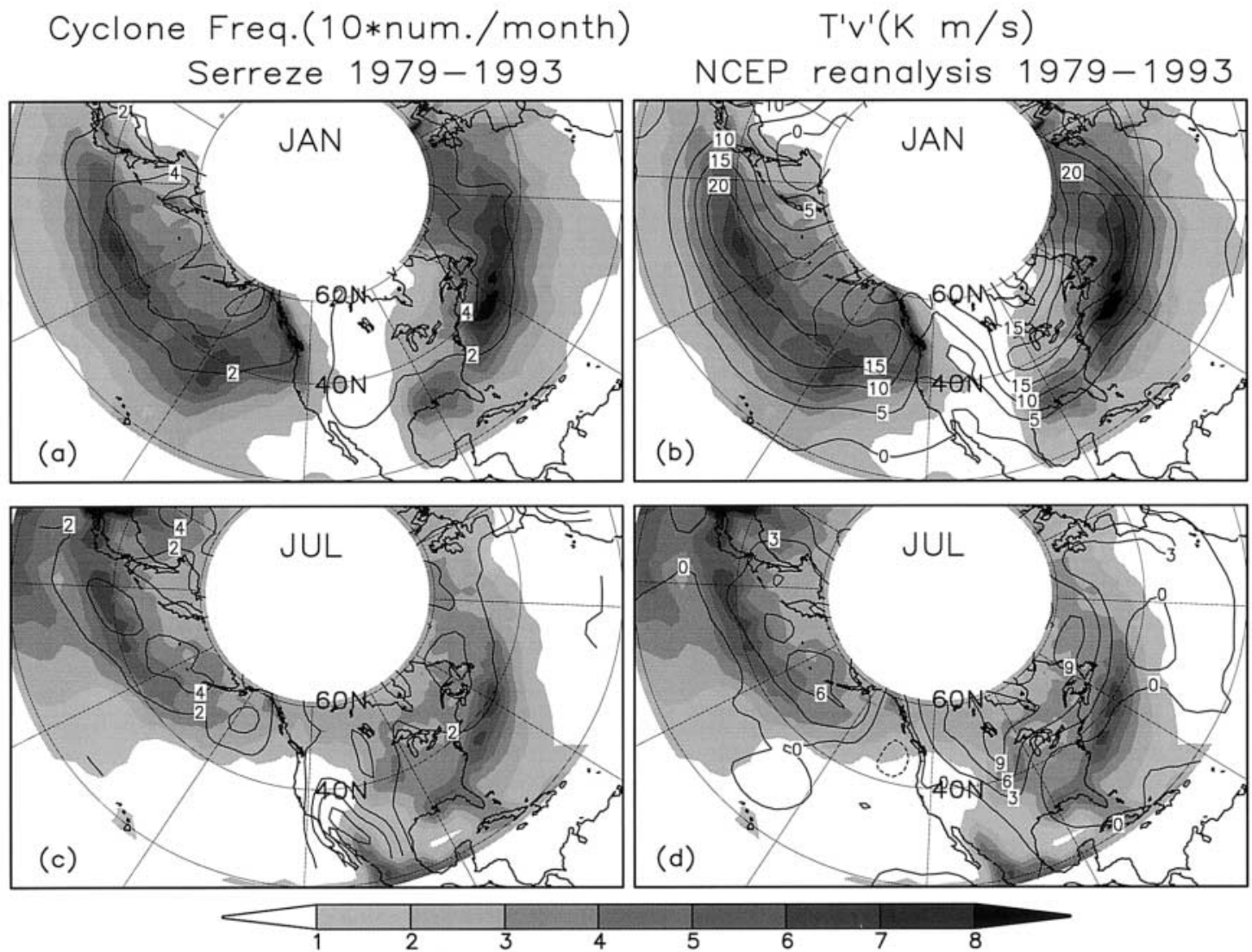

5

6

7

8

Fig. 9. Precipitation of the GPCP for 1988-2000 (shading) and frequency of mobile cyclones after Serreze (1995) for 1979-1993 (contours with interval of $0.2 /$ month) over a zone between $20^{\circ} \mathrm{N}$ and $60^{\circ} \mathrm{N}$ in January (a), as in (a) except meridional temperature flux by T'v' at $700 \mathrm{hPa}$ for $1979-$ 1993 (contours with interval of $5 \mathrm{~K} \mathrm{~m} / \mathrm{s}$ ) (b), as in (a) except for July (c), and as in (b) except for July and contour interval is $3 \mathrm{~K} \mathrm{~m} / \mathrm{s}(\mathrm{d})$.

Two significant cyclone tracks defined as the maximum zones of cyclone frequency are observed over the North Pacific and the North Atlantic. In winter (January), the cyclone tracks extends along $\sim 50^{\circ} \mathrm{N}$, and most parts of the SMPZs shift to the south from the cyclone tracks. Precipitation is strong over the eastern Pacific at $\sim 40^{\circ} \mathrm{N}$ in spite of few surface cyclones. In summer (July), the mid-latitude portions of the SMPZs to the north of $40^{\circ} \mathrm{N}$ almost agrees with the cyclone tracks. Cyclone frequency is low for the western portions of the SMPZs located in the subtropics, especially those over the western Atlantic and eastern North America.

The cyclone track is not always a proper index representing baroclinic wave activity. Wallace et al. (1988) pointed out that surface cyclones were more apt to shift to the higher latitudes than baroclinic zones over the eastern part of the NH oceans during winter. This phenomenon was explained by superimposing cyclones to semi-permanent low-pressure systems prevailing during the winter. There are many possible indexes to describe baroclinic wave activities. Here we adopt a meridional temperature flux by T'v' in the lower troposphere as an index similar to Hoskins and Valdes (1990). The right panels of Fig. 9 show T'v' at $700 \mathrm{hPa}$ averaged for 1979-1993, obtained from the NCEP-NCAR reanalysis data superimposed on the precipitation fields. Here the prime denotes the deviation from the local monthly average. Two significant zones of large flux exist over the North Pacific and the North Atlantic. The latter extends to eastern North America. We 

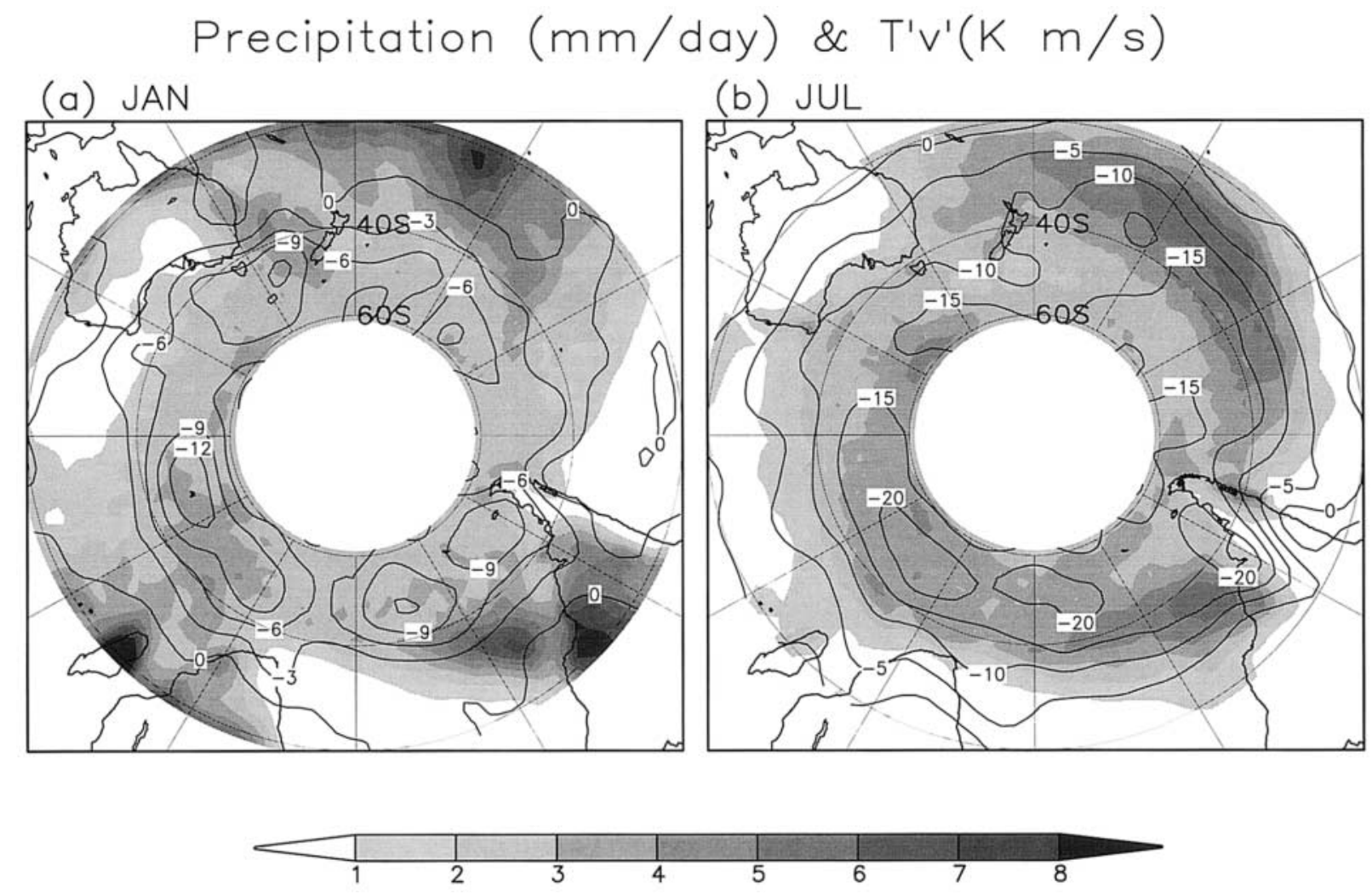

Fig. 10. Precipitation of the GPCP for 1988-2000 (shading) and meridional temperature flux by T'v' at $700 \mathrm{hPa}$ for $1979-1993$ (contours with interval of $2 \mathrm{~K} \mathrm{~m} / \mathrm{s}$ ) between $20^{\circ} \mathrm{S}$ and $60^{\circ} \mathrm{S}$ in January (a). As in (a) except for July and contour interval is $5 \mathrm{~K}$ (b).

refer to these zones as storm tracks. In winter (January), the storm tracks are located to the south of surface cyclone tracks over the eastern part of the $\mathrm{NH}$ oceans, as stated by Wallace et al. (1988). The displacement between the SMPZs and the storm tracks is much smaller than for the cyclone tracks. However, the SMPZs are located in the lower latitudes by $5^{\circ} \sim 10^{\circ}$ except over the central Pacific. In summer (July), the storm tracks correspond to the cyclone tracks. The eastern portions of the SMPZs correspond to the storm tracks. For the western portion of the SMPZs, however, the flux is small in spite of strong precipitation.

We then compare the SMPZs and frequency of surface mobile cyclones in the $\mathrm{SH}$ after the Fig. 10 of Sinclair (1994) derived from the ECMWF reanalysis. The cyclones are defined as the minimum center of relative vorticity of geostrophic wind at $1000 \mathrm{hPa}$ detected in a $63 \times 63$ polar stereographic grid centered on the South Pole, with the maximum spacing of $2.66^{\circ}$ latitude at the Pole. Relative vorticity can derive cyclonic circulation embedded in the mean westerly, but the center of the minimum vorticity shifts to the lower latitudes from the centers of minimum SLP, when the mean westerly is strong (Sinclair, 1994). Only migratory cyclones, whose distance in their lifecycle exceeded $10^{\circ}$ longitude, are shown in that figure.

In winter, surface cyclones increase in the mid-latitudes at $40^{\circ} \mathrm{S} \sim 50^{\circ} \mathrm{S}$ and almost falls on the circumpolar precipitation maximum over the South Atlantic and Indian Oceans. However, the SMPZs over the South Pacific and the western South Atlantic are displaced to the lower-latitudes of the cyclone tracks. In summer, cyclone frequency is low around the western portions of the SMPZs located in the subtropical latitudes. Circumpolar precipitation over the southern ocean is not strong in summer, in spite of many mobile cyclones concentrated around $50^{\circ} \mathrm{S} \sim 60^{\circ} \mathrm{S}$. 
Figure 10 shows T'v' at $700 \mathrm{hPa}$ averaged for 1979-1993 superimposed on the precipitation fields for the $\mathrm{SH}$ in winter and summer. In winter (July), most portions of the SMPZs are elongated along the northern edge of the storm tracks, except those over the Indian Ocean. In summer (January), the western portions of the SMPZs are located in the subtropical latitudes out of the storm tracks. These features are similar to the results for the $\mathrm{NH}$, i.e., many portions of the SMPZs shift to the lower latitudes from the storm tracks in winter and the subtropical portions of the SMPZs are accompanied with weak temperature flux in summer. The latter feature is consistent with Kodama (1992, 1993), who showed that the western portions of the SMPZs were characterized as convergence and frontal zones with no strong baroclinicity. Kodama (1993) pointed out that strong precipitation in these portions was maintained by moisture flux convergence produced by the interaction of low-level monsoon circulation and upper-level subtropical jets. Moreover, strong precipitation in the subtropical portions of the SMPZs in warm seasons is frequently observed around meso-scale cyclones (e.g., Matsumoto et al. 1970; Vincent 1985), which cannot be fully captured by Serreze's scheme.

Previously, we found that the large-scale configuration and precipitation intensity of the SMPZs were similar between fall and winter (e.g., Figs. 5 8). We find similar relationships between the SMPZs and the storm tracks in fall as in winter, i.e., many portions of the SMPZs shift from the storm tracks. We caution that identifying the SMPZs as storm tracks is not correct for many portions of the SMPZs, especially those in fall and winter, and the subtropical portions in summer.

\section{Vertical structure of precipitation of the SMPZs}

To clarify the precipitation mechanisms of the SMPZs, we study seasonal variations of the vertical structure of precipitation and clouds, using 3D data of precipitation from the PR observations and cloudiness from the ISCCPD2 data. Figure 11 shows the echo-top height of the PR observations, and upper and lowlevel cloudiness in winter and summer in each hemisphere. The low (upper)-level cloudiness is defined as cloudiness for clouds with a top pressure larger than $680 \mathrm{hPa}$ (less than 440 $\mathrm{hPa}$; low-level cloudiness does not count the low-level clouds covered by higher-level clouds.

The echo-top height around the SMPZs is $\sim 5 \mathrm{~km}$ in summer, i.e., over the western North Pacific and Atlantic in July, and the central South Pacific and the western South Atlantic in January, and $3 \sim 4 \mathrm{~km}$ in winter, i.e., over the North Pacific and the North Atlantic in January, and the South Pacific and the South Atlantic in July. The echo-top height is somewhat lower (less than $3 \mathrm{~km}$ ) for the SMPZ over the western North Pacific in winter. In summer, upper-level cloudiness is large $(2 / 10 \sim 4 / 10)$ along the SMPZs, although comparable lowlevel cloudiness $(2 / 10 \sim 4 / 10)$ is also found. Large upper-level cloudiness is also maintained around the SMPZs in winter, except over the western North Pacific where the upper-level cloudiness is small, and low-level cloudiness is large.

Figure 12 shows seasonal variation of zonal averaged convective and stratiform precipitation and the echo-top height over ocean. The variation in the mid-latitudes of $30^{\circ}-36^{\circ}$ nearly corresponds to those of the SMPZs, because the precipitation over the mid-latitude oceans is concentrated in the SMPZs. In the midlatitudes, stratiform rainfall largely exceeds the convective ones in summer. Contribution of convective precipitation increases in fall and winter, although the intensity of stratiform precipitation is almost twice as large as the convective ones even in those seasons. Seasonal variation of the zonal averaged echo-top height is not as great. The echo-top height changes between $\sim 4 \mathrm{~km}$ in summer, and $\sim 3.5 \mathrm{~km}$ in fall and winter.

We then investigate the vertical structure of precipitation for each portion of the SMPZs based on the PR observations. The upper-left panel of Fig. 13 shows the histograms of the echo-top height for convective, stratiform, and total precipitation over the western North $\mathrm{Pa}$ cific $\left(30^{\circ} \mathrm{N} \sim 37^{\circ} \mathrm{N}\right.$ and $\left.150^{\circ} \mathrm{E} \sim 180^{\circ}\right)$ around the lower-latitude portion of the SMPZ in summer. Two peaks are found; one is at $4 \sim 5 \mathrm{~km}$ and the other at $\sim 2 \mathrm{~km}$ ASL. Similar double deck structures are generally observed over tropical and subtropical oceans (Short and Nakamura 2000). Here, a rapid decrease below $2 \mathrm{~km}$ is 


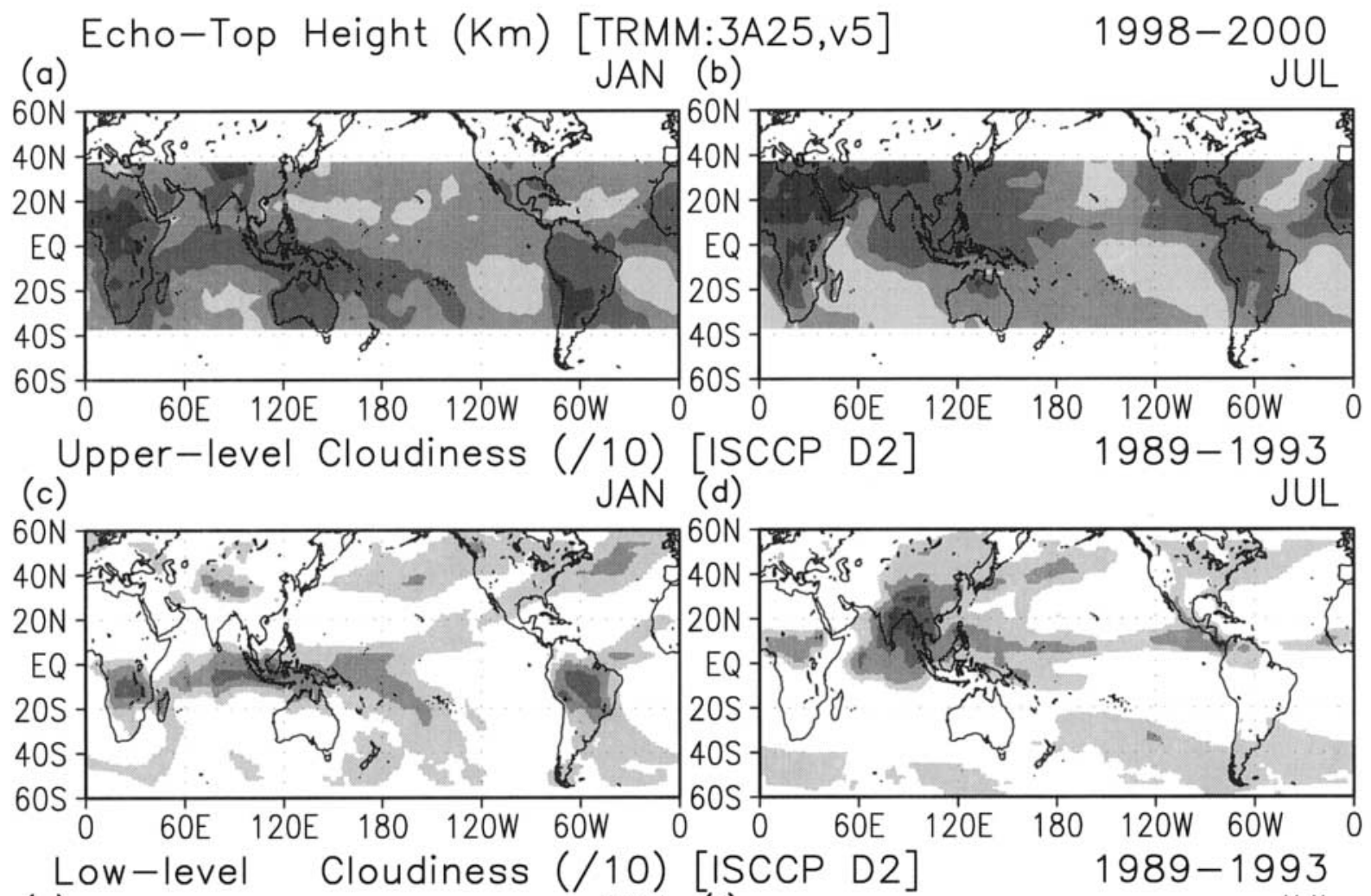
(e) JAN (f) JUL

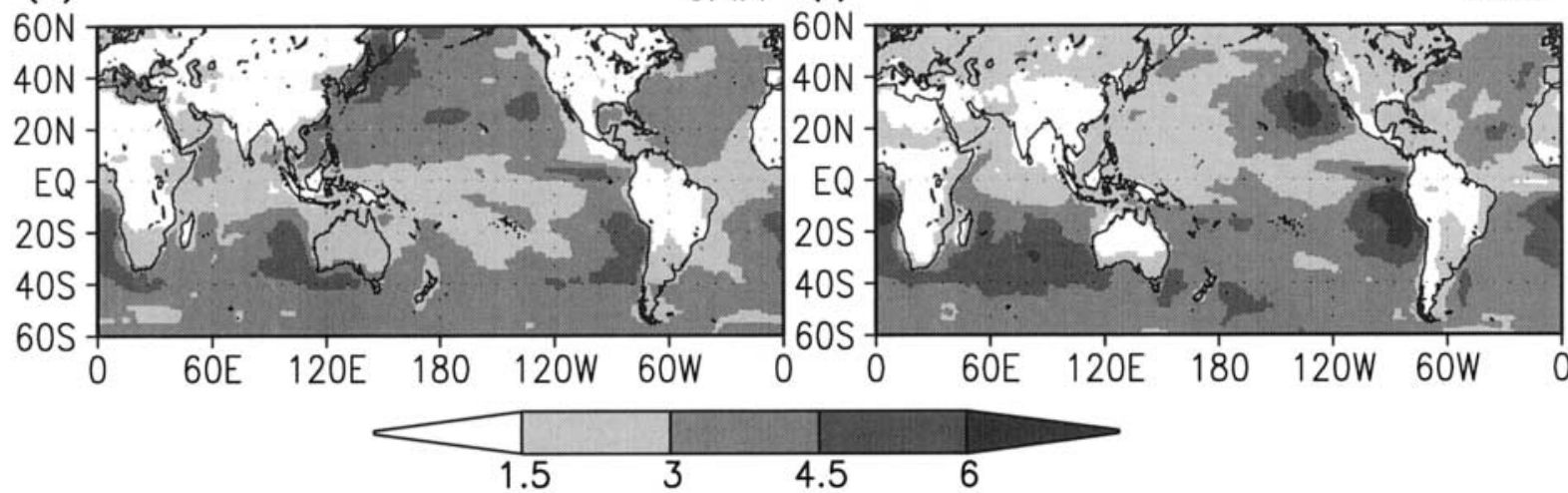

Fig. 11. Mean echo-top height in January (a) and July (b) derived from PR observations averaged for 1998-2000. (c) and (d) are the same as (a) and (b), respectively, except for mean upper-level cloudiness of ISCCP-D2 data averaged for 1989-1993. (e) and (f) are the same as (c) and (d), respectively, except for mean low-level cloudiness.

partly artificial due to observation failure caused by ground clutter, because the lower limit of the PR observation free from ground clutter varies between $0 \mathrm{~km}$ and $\sim 2 \mathrm{~km}$, depending on the swath angle from the nadir. The upper peak at $\sim 5 \mathrm{~km}$ is much larger than the lower one. In the both peaks, stratiform precipitation is dominant.
The upper panels of Fig. 13 also show the vertical profiles for mean precipitation intensity and for the vertical derivative of precipitation intensity, which approximately corresponds to the generation rate of precipitation (strictly speaking, the rate of generation minus evaporation) of each layer. The near surface rain, which is defined as the precipitation at 
Seasonal Variation

\section{TRMM-PR[v5] over Ocean 1998-2000}

(a) Convective rain at $2 \mathrm{~km}$ ( $\mathrm{mm} /$ day)

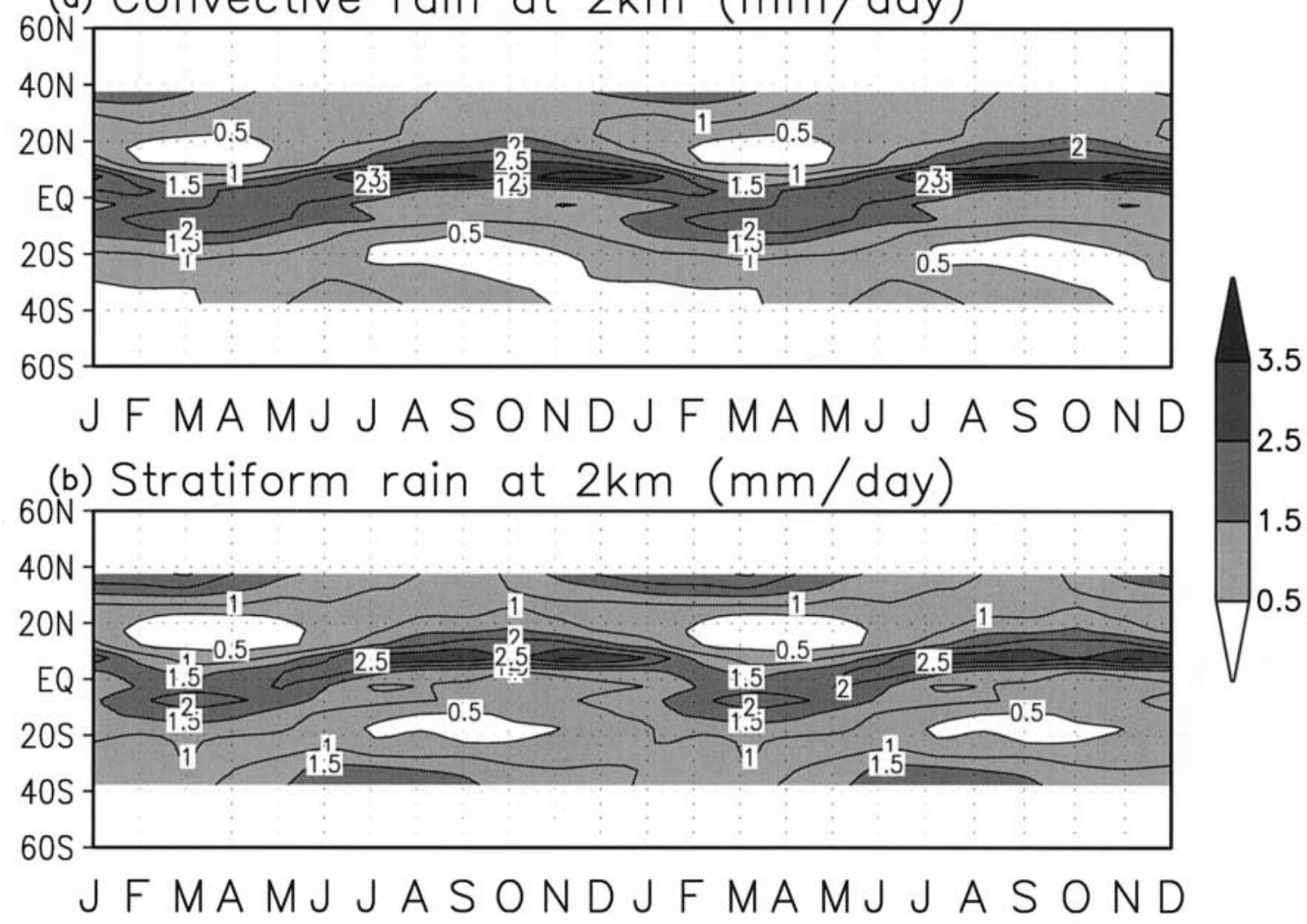

(c) Echo-Top Height ( $\mathrm{km}$ )

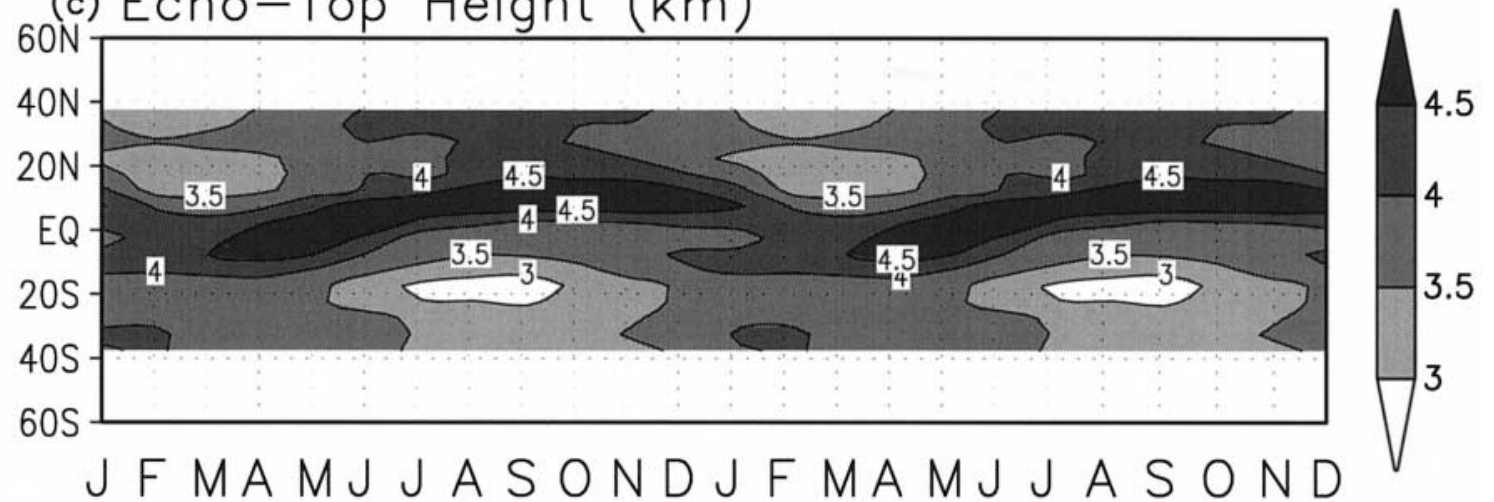

Fig. 12. Seasonal variation of zonal averaged precipitation over oceans for convective (a) and stratiform (b) precipitation at $2 \mathrm{~km} \mathrm{ASL}$. As in (a) except for echo-top height (c). All panels are derived from PR observations in 1998-2000.

the lowest level for the PR observations free from surface clutter, is shown at a height of $0 \mathrm{~km}$ in these graphs, though the near surface rain is a kind of ensemble mean of precipitation between $0 \mathrm{~km}$ and $\sim 2 \mathrm{~km}$. The ratio of convective precipitation intensity to the total, is larger than the corresponding ratio observed in echo-top height frequency (upper-left panel of 
Western North Pacific (30N-37N, 150E-180) (JULY)

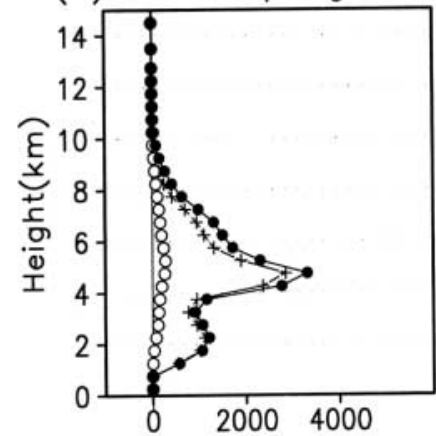

(a) Echo-Top Hght Hist. (b) Precip. Int.

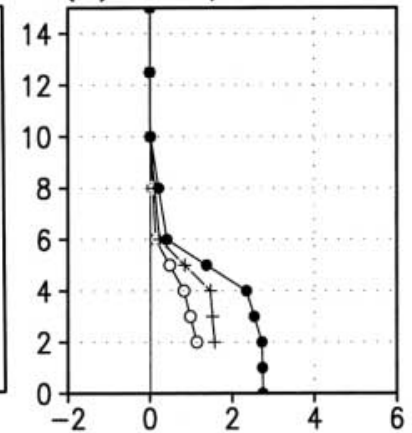

(c) $\mathrm{D}$ (Prec.) $/ \mathrm{Dz}$

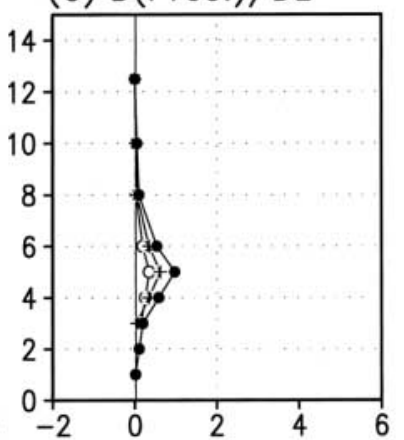

Western North Pacific (30N-37N, 150E-180) (JANUARY)

(d) Echo-Top Hght Hist. (e) Precip. Int.
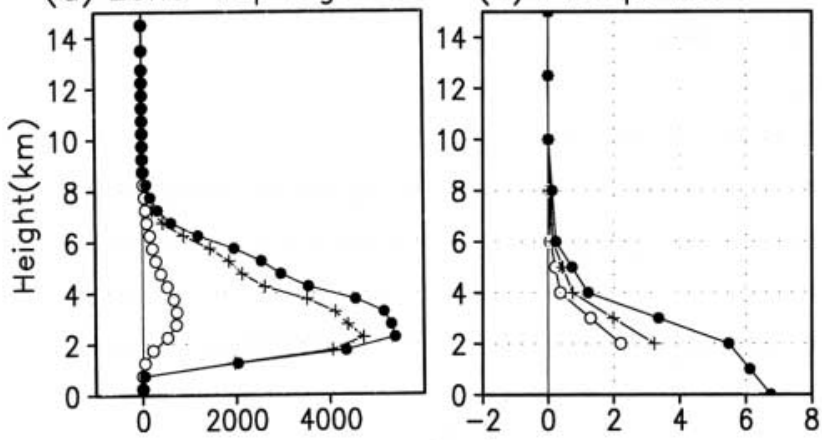

(f) $D($ Prec.) $/ D z$

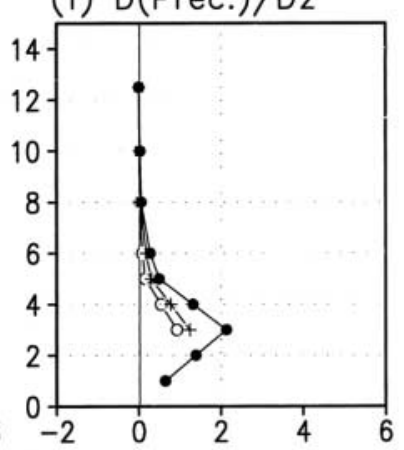

Western North Atlantic (30N-37N, 70W-40W) (JANUARY)

(e) Echo-Top Hght Hist. (h) Precip. Int.
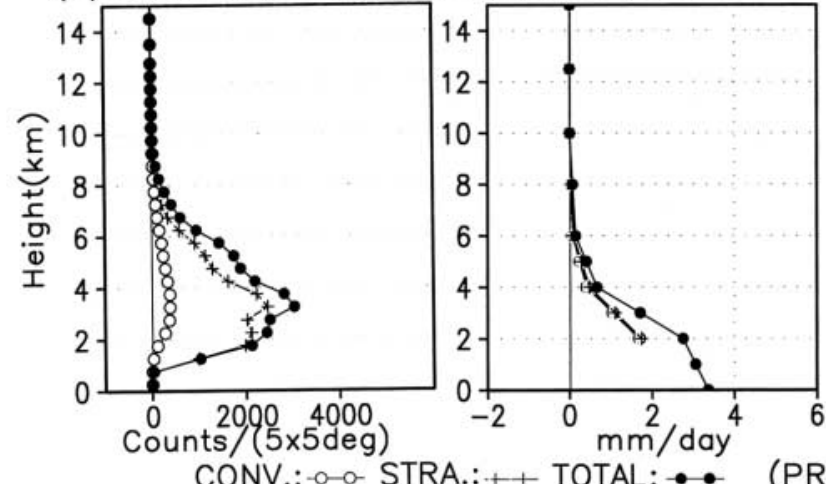

(i) $\mathrm{D}$ (Prec.) $/ \mathrm{Dz}$

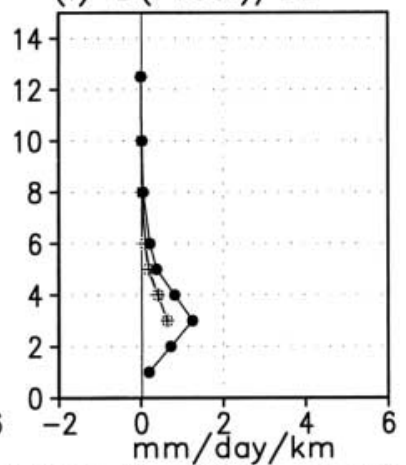

(PR:3A25,v5, 1998-2000)

Fig. 13. Upper panels: Histograms of echo-top height for convective (open circles), stratiform (crosses), and total (closed circles) precipitations over the western North Pacific $\left(30^{\circ} \mathrm{N}-37^{\circ} \mathrm{N}\right.$ and $150^{\circ} \mathrm{E}-180^{\circ}$ ) in July derived from PR observations in 1998-2000 (a). As in (a) except for the vertical profiles of precipitation intensity for each category (b). Near surface rain (refer to the text) is shown at $0 \mathrm{~km}$ ASL in this graph. As in (b) except for vertical derivative of precipitation intensity (c). Middle panels: As in upper panels except in January. Lower panels: As in middle panels except for the western North Atlantic $\left(30^{\circ} \mathrm{N}-37^{\circ} \mathrm{N}\right.$ and $\left.40^{\circ} \mathrm{W}-70^{\circ} \mathrm{W}\right)$.

Fig. 13). This indicates that mean precipitation intensity is greater for convective precipitation events than for stratiform ones. Major generation of precipitation occurs at $\sim 5 \mathrm{~km}$, and the generation is somewhat stronger for stratiform precipitation, than for convective one. These results indicate that deep stratiform and convective precipitations with tops at the middle 
troposphere mainly contribute to the strong precipitation of the SMPZs over mid-latitude oceans in summer. These results are consistent with Hirasawa et al. (1995) who showed the coexistence of convective and stratiform precipitation along the SMPZ to the east of Japan in early summer.

The middle panels of Fig. 13 are the same as the upper ones except in winter. Frequency of shallow precipitation with the echo-top height at $\sim 2 \mathrm{~km}$ ASL largely increases. The lower peak at $\sim 2 \mathrm{~km}$ is dominant in the echo-topheight frequency and the generation rate of precipitation is large in the lower troposphere at $\sim 3 \mathrm{~km}$ with both stratiform and convective precipitation. Generation rate of precipitation in the middle troposphere is low in spite of a large frequency of echo-top height. This means a large contribution of shallow precipitation to the total along the SMPZ. This is consistent with the fact that many shallow clouds appeared over this ocean, when the cold air of the Asian winter monsoon outbreaks.

Lower panels are the same as in the middle ones, except for the western North Atlantic $\left(30^{\circ} \mathrm{N} \sim 37^{\circ} \mathrm{N}\right.$ and $\left.70^{\circ} \mathrm{W} \sim 40^{\circ} \mathrm{W}\right)$ covering the western portion of the SMPZ over the North Atlantic, where strong precipitation is observed to the south of the storm track (Fig. 9). Contradictory to the western North Pacific in winter, the upper peak $(\sim 4 \mathrm{~km})$ exceeds the lower one $(\sim 2 \mathrm{~km})$ in the frequency of echo-top height. Nevertheless, shallow precipitation largely contributes to the total as shown in the vertical profiles of precipitation and generation rate. The generation rate of precipitation in the middle troposphere is low in spite of the high frequency of echo-top height.

Vertical structure of precipitation of the other portions of the SMPZs is also examined for summer and winter. In summer, the vertical structure is similar to that of the SMPZ over the western North Pacific, i.e., frequent precipitation with middle-level echo-top height and large generation rates of precipitation in the middle troposphere. In winter, the structure is similar to that over the western North Atlantic, i.e., frequent precipitation with middle-level echo-top height, greater degree of upper cloudiness, and large generation of precipitation in the lower troposphere. A preliminary scan of quick-look images of $\mathrm{PR}$ observations indicates that most of the precipitation with middle-level echo-top-height appears in cyclones or their fronts in winter (not shown).

The western portion of the SMPZ over the North Pacific in winter is somewhat exceptional, because frequency of the upper peak in echo-top height histogram is much smaller than that of the lower peak. Moreover, the upper-level cloudiness is smaller, and mean echo-top height is lower, than the other portions of the SMPZs in winter. These features are observed only in mid-winter between December and February (not shown). Nakamura (1992) pointed out that cyclone activity was much weaker over the western North Pacific than the western North Atlantic in mid-winter. Exceptional weakness of the upper peak may be ascribed to the suppressed cyclone activity in mid-winter over this ocean.

Previously, we found that the large-scale characteristics of the SMPZs were similar between fall and winter (e.g., Figs. 5 8). For entire portions of the SMPZs in fall, the vertical structure of precipitation is similar to that of the SMPZ over the western North Atlantic in winter. Shallow precipitation largely contributes to maintaining the precipitation of the SMPZs in both fall and winter (not shown).

The contribution of large amounts of shallow precipitation to the total of the SMPZs in fall and winter may be related to the shift of the SMPZs to the lower latitudes from the storm tracks during these seasons. This is because the shallow precipitation likely appears when air-sea temperature difference is large, and the temperature difference may be larger in the equatoward side of the baroclinic waves, where the sea surface temperature is higher than the poleward side. More process studies using snapshot data are necessary to confirm this hypothesis. We also found much upper-level cloudiness and frequent precipitation with middle-level echo-top height around the SMPZs even for their portions apart from the storm tracks in winter, e.g., the SMPZs over the eastern North Pacific and the western South Atlantic. Mobile fronts may maintain this middle-level precipitation. Actually, cold fronts frequently appear around the east coast of South America and the western South Atlantic in winter (Marengo et al. 1997, Satyamurty et al. 1998). 


\section{Summary}

We studied large-scale precipitation in the subtropics and the mid-latitudes based on new climatological precipitation datasets derived from satellite observations: the GPCP and TRMM level-3 products. Zonal mean precipitation in the mid-latitudes had peaks at $\sim 40^{\circ}$ only over oceans, while it was flat over land. The mid-latitude peaks over oceans appeared throughout the year and intensified in fall and winter. In the subtropics, precipitation intensified in summer over both land and oceans.

The mid-latitudes peaks in the zonal mean precipitation were ascribed to significant precipitation zones that developed over oceans in the mid-latitudes and the subtropics, which were referred to as SMPZs in this study. The SMPZs were not well represented in previous climatological studies derived from surface observations. The SMPZs appeared throughout the year with seasonal changes in their configuration. In summer, the SMPZs extended diagonally between the subtropics and the midlatitudes from tropical monsoon rainfall areas. In fall and winter, the SMPZs zonally extended in the mid-latitudes with precipitation as strong as in summer. These seasonal changes of the SMPZs produced the summertime intensification in subtropical oceans and the fallto-winter intensification in mid-latitude oceans observed in zonal mean precipitation. The midlatitude portions of the SMPZs existed near the storm tracks defined by high baroclinic wave activities. However, many portions of the SMPZs were displaced to the lower latitudes from the storm tracks in fall and winter. Baroclinic activity was weak over the subtropical portions of the SMPZs in summer, which were characterized as convergence zones of moisture flux.

Vertical structure of precipitation observed by TRMM-PR suggested both deep stratiform and convective precipitation contributed to the strong precipitation along the SMPZs in summer, while shallow stratiform and convective precipitation largely contributed to the precipitation of the SMPZs in fall and winter, although weak but deep (extending to the midtroposphere) stratiform precipitation was also frequently observed along the SMPZs, except over the western North Pacific in mid-winter.

\section{Acknowledgements}

The authors thank Prof. H. Nakamura for suggesting appropriate references concerning the storm tracks and providing the heat flux data compiled by himself with Mr. Shimpo. We utilized several precipitation datasets provided by NCDC/NOAA and GSFC/NASA, and Serreze's Arctic Cyclone Track Dataset, 1963-1993 provided by NSIDC-ARCSS, via Internet access. Dr. Hayasaki provided the information about the cyclone dataset. Constructive comments from anonymous reviewers were valuable for revising the original manuscript. This study was done as a cooperative study between NASDA and Hirosaki University. This study was partly supported by Grant-in-Aid for Scientific Research (C) by JSPS and Grant-in-Aid for Scientific Research on Priority Areas (B) by MEXT. The Grid Analysis and Display System developed at COLA, University of Maryland, was utilized to draw figures in this paper.

\section{References}

Arkin and Meisner 1987: The relationship between large-scale convective rainfall and cold front over the western Hemisphere during 19821984. Mon. Wea. Rev., 115, 51-74.

Dorman, C.E. and R.H. Bourke, 1979: Precipitation over the Pacific Ocean, $30^{\circ} \mathrm{S}$ to $60^{\circ} \mathrm{N}$. Mon. Wea. Rev., 107, 896-910.

- 1981: Precipitation over the Atlantic Ocean, $30^{\circ} \mathrm{S}$ to $70^{\circ}$ N. Mon. Wea. Rev., 109, 554-563.

Ferraro, R.R., 1997: Special sensor microwave imager derived global rainfall estimates for climatological applications. J. Geophys. Res., 102, 16715-16735.

Gates, W.L., J.M. Boyle, C. Covey, C.G. Dease, C.M. Doutriaux, R.S. Drach, M. Fiorino, P.J. Gleckl;er, J.J. Hnilo, S.M. Marlais, T.J. Phillips, G.L. Potter, B.D. Santer, K.R. Sperber, K.E. Taylor, and D.N. Williams, 1999: An overview of the results of the atmospheric model intercomparison project (AMIP I). Bull. Americ. Meteor. Soc., 80, 29-55.

Hirasawa, N., K. Kato, and T. Takeda, 1995: Abrupt change in the characteristics of the cloud zone in subtropical East Asia around middle of May. J. Meteor. Soc. Japan, 73, 221-239.

Hoskins, B.J. and P.J. Valdes, 1990: On the existence of storm-tracks. J. Atmos. Sci., 47, 18541864.

Huffman, G.J., R.F. Adler, P. Arkin, A. Chang, R. Ferraro, A, Gruber, J. Janowiak, A. McNab, B. Rudolf, and U. Schneider, 1997: The global 
precipitation climatology project (GPCP) combined precipitation dataset. Bull. Amer. $\mathrm{Me}$ teor. Soc., 78, 5-20.

and D.T. Bolvin, 2001: GPCP version 2 combined precipitation data set documentation. pp. 41.

Jaeger, L., 1976: Monatskarten des Niederschlags fur die ganze Erde. Ber. Dtsch. Wetterdienstes, 139(Band 18), 33pp. and plates.

Janowiak, J.E., P.A. Arkin, P. Xie, M.L. Morrissey, D.R. Legates, 1995: An examination of the east Pacific ITCZ rainfall distribution. J. Climate, 8, 2810-2823.

, A. Gruber, C.R. Kondragunta, R.E. Livezoy, and G.J. Huffman, 1998: A comparison of the NCEP-NCAR reanalysis precipitation and the GPCP raingauge-satellite combined dataset with observational error considerations. J. Climate, 11, 2960-2979.

Kodama, Y.-M., 1992: Large-scale common features of subtropical precipitation zones (the Baiu frontal zone, the SPCZ and the SACZ) Part I: Characteristics of subtropical frontal zones. $J$. Meteor. Soc. Japan, 70, 813-836.

, 1993: Large-scale common features of subtropical convergence zones (the Baiu frontal zone, the SPCZ and the SACZ) Part II: Conditions of the circulations for generating the STCZs. J. Meteor. Soc. Japan, 71, 581-610.

Legates, D.R. and C.J. Willmott, 1990: Mean seasonal and spatial variability in gaugecorrected, global precipitation. International J. of Climatology, 10, 111-127.

Marengo, J., A. Corenejo, P. Satyamurty, and C. Nobre, 1997: Cold surges in tropical and extratropical South America: the strong event in June 1994. Mon. Wea. Rev., 125, 2759-2786.

Matsumoto, S., S. Yoshizumi, and M. Takeuchi, 1970: On the structure of the Baiu front and associated intermediate-scale disturbances in the lower atmosphere. J. Meteor. Soc. Japan, 48, 479-491.

Nakamura, H., 1992: Midwinter suppression of baroclinic wave activity in the Pacific. J. Atmos. Sci., 49, 1629-1642.

, T. Izumi, and T. Sampe, 2002: Interannual and decadal modulations recently observed in the Pacific Storm Track activity and the East Asian winter monsoon. J. Climate, 15, 18551874.

NASA/GSFC, 2001: Tropical rainfall measuring mission science data and information system. Interface control specification between the tropical rainfall measuring mission science data and information system (TSDIS) and the TSDIS Science User (TSU) TSDIS-P907,
Volume 4: File specifications for TRMM products-level 2 and level 3. pp. 69.

Petty, G.W., 1995: Frequencies and characteristics of global oceanic precipitation from shipboard present weather reports. Bull. Amer. Meteor. Soc., 76, 1593-1616.

Rossow, W.B. and R.A. Schiffer, 1999: Advances in understanding clouds from ISCCP. Bull. Amer. Meteor. Soc., 80, 2261-2287.

Rudolf, B., 1993: Management and analysis of precipitation on a routine basis. Proc. Internet. WMO/IAHS/ETH SYMP. On precipitation and evaporation, Slovak Hydromet. Inst., Bratislava, Sept. 1993, 1, 69-76.

Satyamurty, P., C.A. Nobre, and P.L. Silva Dias, 1998: South America. Meteorology of the Southern Hemisphere. Edited by D.J. Karoly and D.G. Vincent. 119-139.

Short, D.A. and K. Nakamura, 2000: TRMM radar observations of shallow precipitation over the tropical oceans. J. Climate, 13, 41074124.

Serreze, M.C., 1995: Climatological aspects of cyclone development and decay in the Arctic. Atmosphere-Ocean, 33, 1-23.

Sinclair, M.R., 1994: An objective cyclone climatology for the Southern Hemisphere. Mon. Wea. Rev., 122, 2239-2256.

Susskind, J., P. Piraino, L. Rokke, L. Iredell, and A. Mehta, 1997: Characteristics of the TOVS pathfinder Path A dataset. Bull. Amer. Meteor. Soc., 78, 1449-1472.

Trewartha, G.T. and L.H. Horn, 1980: An introduction of Climate. Fifth edition. McGraw-Hill. pp. 416.

Vincent, D.G., 1985: Cyclone development in the South Pacific convergence zone during FGGE, 10-17 January 1979. Quart. J. Roy. Meteor. Soc., 111, 155-172.

Wallace, J.M., G.-H. Lim, and M.L. Blackmon, 1988: Relationship between cyclone tracks, anticyclone tracks and baroclinic waveguides. $J$. Atmos. Sci., 45, 439-462.

Wilheit, T., A. Chang, and L. Chiu, 1991: Retrieval of monthly rainfall indices from microwave radiometric measurements using probability distribution function. J. Atmos. Oceanic Technol, 8, 118-136.

Xie, P. and P.A. Arkin, 1997: Global precipitation: A 17-year monthly analysis based on gauge observations, satellite estimates and numerical model outputs. Bull. Amer. Meteor. Soc., 78, 2539-2558.

, 1998: Global monthly precipitation estimates from satellite-observed outgoing longwave radiation. J. Climate, 11, 137-164. 